\title{
Multinational Corporations and Political Violence: Trends and Forecasts
}

\author{
Alero Akporiaye ${ }^{1}$, Vito D'Orazio ${ }^{2}$ and Clint Peinhardt ${ }^{2}$ \\ ${ }^{1}$ Rhode Island School of Design \\ ${ }^{2}$ University of Texas at Dallas
}

\begin{abstract}
Multinational corporations (MNCs) increasingly worry about the threat of targeted violence, particularly in the form of terrorist attacks. Why do terrorists target MNCs and which factors are sufficiently predictive to matter to decision makers? We identify potential theoretical explanations from the literature on MNCs and transnational terrorism. Then, using conflict forecasting methods, we show the best predictors are whether a country experienced attacks before, and whether such attacks are common in the region. In addition, exogenous factors such as income improve performance, but many of the typical explanations for transnational terrorism, such as those involving regime type, do not help to identify MNC targets. Furthermore, despite using multiple behavioral and economic measures of MNC activity, it does not appear that their actions have much of an impact on whether MNCs are targeted. Future research on corporate targets of political violence would benefit from analysis at the firm and group level.
\end{abstract}

Keywords: terrorism, political violence, multinational corporations, conflict forecasting 


\section{Introduction}

Multinational corporations (MNCs) face numerous and diverse risks in the course of doing business, particularly in emerging markets and developing countries. Those risks can be transactional, financial, or political (Luo, 2009). Transactional risks include potential disruptions from employee turnover or failure of a business partner to meet deadlines or quality requirements. Financial risks include exchange rate risk or adjustments in assets or liabilities due to unanticipated market changes. Political risks are broader, and can include threats to ownership rights, changes in regulation, or other disruptions in business activity.

Scholars of political risks for MNCs have focused primarily on actions by the governments of host states, who are undoubtedly the primary source of some sorts of risks. Foreign investors who cannot convert profits to hard currency or liquidate assets can often blame the host country's central bank. Those whose assets are expropriated outright can usually thank chief executives or legislatures. Those who are subject to creeping expropriation in the form of increasing regulation or taxation may be the target of bureaucracies or subnational entities. Increasingly, though, MNCs face risks that emanate from non-state actors (Jakobsen, 2010). Nowhere is that clearer than in the case of political violence, especially terrorism.

There have been a number of high profile and recent terrorist attacks on MNCs. On 14 January 2016, ISIS-funded suicide bombers chose to detonate their bombs at a Starbucks coffee shop in Jakarta, Indonesia. Four civilians were killed and 23 were injured in the attack, including a Starbucks security guard and four customers. ${ }^{1}$ Concerned about follow-on attacks, the multinational shut down all 200 of its stores in the country for several days. In February, 2016, rebel groups in Nigeria began attacking Royal Dutch Shell's oil pipeline Forcados due to the end of payments from the Nigerian governments that had been used to deter such attacks. ${ }^{2}$ Attacks promptly escalated, and the government resumed those payments in August. In late August, 2016, anti-government protesters in Ethiopia set fire to and destroyed several flower farms owned by the Dutch firm Esmeralda Farms, which then closed operations. ${ }^{3}$

According to Berne Union (2016), a collection of providers of political risk insurance (PRI), political violence dominated other categories of PRI payouts between 2011 and 2015. Figure 1 shows the payouts for political violence, ex-

\footnotetext{
${ }^{1}$ https://tinyurl.com/y3zkghxf, accessed 16 August 2019.

${ }^{2}$ https://tinyurl.com/yym9t2qw, accessed 16 August 2019.

${ }^{3}$ https://tinyurl.com/yyvyvwbe, accessed 16 August 2019.
} 


\section{Political Risk Investment Insurance Claims}

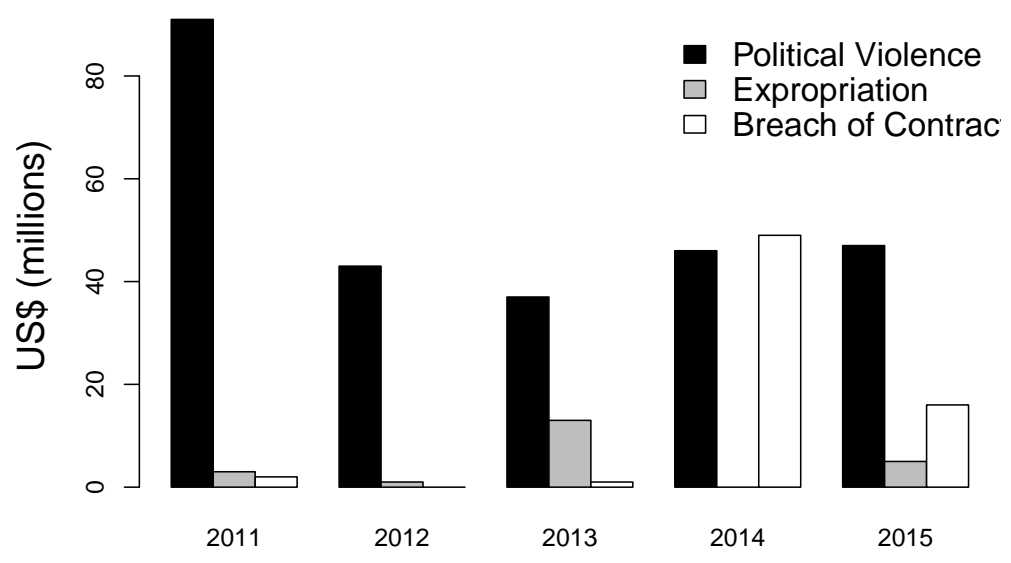

Figure 1: PRI Claim Payouts

propriation, and breach of contract. ${ }^{4}$ The only year where political violence is not the largest share is in 2014, where it was slightly edged out by breach of contract payouts. In all other years, payouts for political violence is greater than expropriation and breach of contract combined. In short, political violence is an increasingly common risk for MNCs, one where risk insurers make larger payouts, but also one to which researchers have paid little attention.

Why are MNCs targets of political violence? Scholars rarely examine this question directly, but often focus instead on how investors respond to political violence, usually in the form of foreign direct investment (FDI) flows. Others examine how political violence affects economic growth. Some scholarship investigates how increases in political violence affects political risk assessment, focusing mostly on civil conflict, in which firms face both indiscriminate and targeted violence. There is a large literature on the causes of transnational terrorism, of which attacks against MNCs are a subset, but the degree to which the explanations are the same has not been assessed (Gaibulloev and Sandler, 2019; Gassebner and Luechinger, 2011).

\footnotetext{
${ }^{4}$ Investment insurance claims paid for political violence totaled $\$ 91$ million in 2011, $\$ 43$ million in 2012, $\$ 37$ million in 2013, $\$ 46$ million in 2014, and $\$ 47$ million in 2015. Equivalent figures for expropriation were $3,1,13,0$, and 5 ; for breach of contract $2,0,1,49$, and 16 (Berne Union, 2016).
} 
Here, we explore the factors that drive terrorist attacks against MNCs and assess the extent to which MNC activity is one of those factors. To do so, we build forecasting models to estimate the risk of terrorism against MNCs at the country-year level of analysis. We begin with a baseline model of transnational terrorism from Gaibulloev et al. (2017). To this model we add variables to capture past MNC attacks, behavioral measures of MNC activity using event data from the Integrated Crisis Early Warning System (ICEWS) (Boschee et al., 2015), and economic measures of activity using FDI stocks (UNCTADSTAT, 2019). We then pare down this set of theoretically relevant variables to identify the best-performing subset.

Our research has two primary findings. First, we show that a six variable model performs best, suggesting models of transnational terrorism, which typically include many more predictors, are overly complex in the case of attacks against MNCs. Furthermore, there are some core differences between our model of attacks against MNCs and transnational attacks generally. For example, we do not find support that regime-type is an important predictor, in contrast to some models of transnational terrorism (Gaibulloev et al., 2017; Savun and Phillips, 2009). On the other hand, we do find support that GDP per capita is a strong predictor of terrorism, and the relationship is found to be non-linear (Enders et al., 2016).

Second, despite our best efforts to capture diverse MNC activities at the country-year level of analysis, these variables are not associated with attacks against MNCs. While there are many potential explanations for this nonfinding, we suggest future research disaggregate the unit of analysis to explore firm and group level interactions. Our model shows that MNC activity is not a strong predictor at the macro level, but it might be that their actions do matter at the micro level.

\section{Multinational Corporations and Political Violence}

When MNCs become the victims of political violence, they may be targeted directly, or they may be swept up in broader conflicts. Most research examines this process only indirectly, focusing on the overall economic impact of political violence. Indeed, violent actors may intentionally attempt to inflict economic costs, and considerable evidence shows that political violence lowers economic activity by reducing risk-taking among economic actors. Most prolonged disruptions occur due to interstate wars (Koubi, 2005; Anderton and Carter, 2001a,b; Marano et al., 2013) or civil wars (Collier, 1999; Murdoch and Sandler, 2002). Not surprisingly, these declines in economic activity also reduce the attractiveness of an economy for foreign investors, including 
MNCs. Here MNCs may be targeted due to their overall impact on the domestic economy, which often shows up as FDI. Unanticipated civil wars have been shown to reduce both the probability and magnitude of FDI levels in the affected country (Li, 2006). Li and Vashchilko (2010) show that between countries that have different levels of economic development, military conflict reduces FDI while alliances between countries increase it. In contrast, others have found that bigger firms with more concentrated ownership, and from particular sectors, are more likely to invest in conflict zones, including mining, agriculture, and high technology (Driffield et al., 2013). Even when new investments avoid host countries with political violence, Barry (2018) demonstrates that existing operations will remain in place under most types of low-level conflict.

Jensen and Young (2008) find that civil conflicts also influence the perception of political risk, which can explain why flows of investment decline. In some ways this is not surprising, since civil conflicts often affect large areas and MNCs that happen to have operations in those areas can easily be affected even if they are not directly targeted. More recent evidence shows that the negative effects of civil war on FDI can be sector-dependent, with primary sector investment continuing in developing countries that are affected by civil war, even as investment in secondary and tertiary sectors is negatively affected (Li et al., 2017). Additionally, the manner in which a civil war ends could affect post-civil war FDI flows. Joshi and Quinn (2018) find that civil war termination based on the negotiation and implementation of a comprehensive peace agreement provides comfort to investors and draws in more FDI flows than other termination mechanisms.

While some MNCs suffer from being in the wrong place at the wrong time, others are targeted directly but still under broader conditions of civil conflict. Along the lines of Kalyvas (2006), a hard line can be drawn between civil war and other forms of political violence, such as riots or criminal acts. Kalyvas' distinction is problematic for us since a targeted act against a MNC during civil war is an act of war, whereas the same act during peacetime is categorized differently, as political violence. Further, Kalyvas distinguishes only between civilians and combatants in such a war. As such, MNCs would be considered civilians in his framework and have greater power to flee the conflict than do most civilians. Fortna (2015) distinguishes instead between indiscriminate political violence that intends to send a political message to a wider audience and targeted political violence that tries to change the behavior of its target. MNCs are clearly affected by both indiscriminate and targeted political violence. Whether they occur as part of a civil conflict is irrelevant, even if civil conflicts affect overall assessments of political risk. In the context of civil war, MNCs-particularly in the extractive sector-are ripe targets for political violence because of their strategic assets. Access and control of valuable nat- 
ural resources like oil and gems have been used by rebels to finance violence against the state and to influence of local populations (Collier and Hoeffler, 2004; Le Billon, 2001; Snyder, 2006; Ross, 2004).

Targeted violence against MNCs, particularly by terrorist groups, may have additional motivations. Several scholars argue that terrorism tries to inflict economic costs by reducing productivity and levels of capital stock, by damaging infrastructure, by scaring away potential tourists, and by forcing governments to spend money on counterterrorism. Econometric evidence is largely consistent with these logics. Enders and Sandler (1996) provide evidence that terrorism reduced FDI in Spain (by 13.5\%) and Greece (by 11.9\%) from the mid-1970s to 1991. In a broader study, Enders et al. (2006) find that terrorism in OECD countries had a small $(1 \%)$ but negative effect on FDI flows from the United States, but that it had no effect in non-OECD countries. Some countries, such as Greece and Turkey, appeared to suffer greater impact. Abadie and Gardeazabal (2008) show that even though terrorism causes direct damage to capital stock, the indirect effects of terrorism are greater thanks to MNCs' mobility. They find that investors divert their assets to other countries in response to terrorist actions, and that a standard-deviation increase in terrorism reduces overall FDI stock by 5\%. Echoing Jensen and Young (2008), Faran (2014) shows that FDI flows into developing countries with expected higher future turmoil risk is lower than countries with lower risk. FDI has also been found to be the cross-border capital flow that is most responsive to terrorism. ${ }^{5}$ Inflows of FDI into developing countries have also been found to be negatively impacted by transnational terrorist attacks (Bandyopadhyay et al., 2014). If terrorists' goals include hurting an economy, they should attack firms with the biggest economic impact, either via employment or perhaps revenue share of the economy.

Bandyopadhyay et al. (2014) argue that terrorists may target the foreign firms of particular governments for strategic reasons. An MNC may have little counterterrorism assistance from its home government, or that assistance may be less effective in a different host country. ${ }^{6}$ Home governments may be able to reduce the impact of terrorism on firms of their nationality via direct military protection or, as Bandyopadhyay et al. (2014) suggest, foreign aid. Lee (2017) finds that counterterrorism aid mitigates the effect of terrorism on FDI flows because it signals to foreign investors that the host country can combat terrorism, thereby shielding their investment.

MNCs can also become targets because of their contributions to economic

\footnotetext{
${ }^{5}$ Among FDI, equity portfolio investments, and lending, Filer and Stanišić (2016) find no evidence that terrorism has an effect on the latter two, but increased terrorist activity dampens FDI inflows.

${ }^{6}$ Bandyopadhyay et al. (2014) denote this "the reduced marginal effect of enforcement."
} 
degradation, socioeconomic stagnation and political marginalization (Ukeje, 2001). In the case of Colombia's armed conflict, MNCs that assisted state or non-state actors to create a permissible environment for their operations could contribute to shaping the terrorist attacks they face (Richani, 2005; Johnston, 2008). Johnston (2008) further argues that such participation creates the possibility of liability for enabling terrorist activity, according to international humanitarian law. Others claim that terrorist attacks against MNCs are symbolic and purposefully draw international attention (Jenkins, 2006).

To summarize, previous work on terrorism suggests several logics why MNCs may be targeted. First, they may play an outside role in the local economy, which terrorists often want to sabotage to reduce support for incumbent governments. Second, MNCs may own specific assets that offer unique political economic advantages. Third, MNCs may represent colonial pasts or Western capitalism to groups whose ideologies directly oppose those ideas. MNCs may therefore be attacked for those symbolic reasons. The first three logics for terrorism are not necessarily due to the MNC's own actions, but a fourth logic mor directly implicates the behavior of MNCs themselves.

We aim not only to advance empirical analysis of political violence against MNCs, but also to examine how the behaviors of MNCs themselves influence such violence. On the one hand, these behaviors can create conflict, such as Royal Dutch Shell's actions in the Niger Delta, or Exxon's use of Indonesian security forces against locals. On the other hand, firms increasingly try to create cooperative environments for local operations via strategies like corporate social responsibility (CSR). Research has shown that adoption of CSR by firms is rooted in national campaigns that cater to specific socioeconomic and political issues, suggesting that firms are cognizant of managing their local environments (Lim and Tsutsui, 2012; Chen and Bouvain, 2009). Programs are used for reasons that include managing public perception, addressing operational harms, reducing social inequities, and contributing to economic development (Ballard and Banks, 2003; Evuleocha, 2005; Idemudia, 2008; Kemp, 2010; Aguirre, 2011; Kemp et al., 2011). For example, Henisz et al. (2014) find that the financial performance of Canadian gold mining MNCs is influenced by their treatment of local stakeholders near their foreign mines. ${ }^{7}$ However, other studies have shown that the effectiveness of CSR for taming the local environment can be called into question (Lompo and Trani, 2013; Idemudia, 2010; Brueckner et al., 2014).

Ideally, to assess the impact of CSR, or local firm behaviors in general, we

${ }^{7}$ The Henisz, Dorobantu, and Nartey (2014) paper involves significant effort collecting event data on one industry; our approach here is attempt a similar exercise with off-the-shelf event data. 
would examine data on individual firms to see which suffered attacks. Such data are not currently available and would require immense effort to collect. We therefore take a broader approach to investigate whether the MNC behaviors are important predictors of terrorism against MNCs. We take event data from automated sources, narrow it to actions involving MNCs, and to build general behavioral measures from these events at the country-year level of analysis. We agree that MNCs should be able to improve local relationships in the host state, as CSR suggests, but we ask specifically whether broad measures of MNC behaviors are associated with retribution in the form of targeted terrorist violence.

In the remainder of this paper, we make several contributions to the study of political violence and MNCs. First, we narrow our focus to a specific set of terrorist attacks, those against MNCs. Second, we examine the determinants of those attacks as compared to broader samples of transnational terrorism. Third, we use data from automated event coding to create behavioral measures of MNCs across countries and use those as additional explanatory variables for terrorist attacks against MNCs. Fourth, we create a forecasting model of terrorist attacks against MNCs. While we find that neither traditional determinants of terrorism nor our broad indicators of corporate behavior have much predictive power, our work suggests some paths forward for future work on this topic.

\section{Data, Methods, and Results}

Thus far, we have discussed the relationship between MNCs and political violence and some potential reasons why terrorists may target MNCs. We have also highlighted some ways that MNCs might mitigate the risks they face. In this section, we use data to model these risks more directly and to assess the role that MNCs might play. Specifically, we build and evaluate a parsimonious forecasting model of terrorist attacks against MNCs. In contrast to causal models that are generally built to estimate a causal relationship, conflict forecasting models are built to quantify the likelihood of conflict. In particular, we are interested in assessing the risks MNCs incur as a function of the actions they take. Do measures of MNC activity help to forecast terrorist attacks against MNCs? If yes, then which behaviors? Such a finding would indicate that governments should consider their relations with MNCs, as well as local MNC behaviors, to combat terrorism. Generally, what factors are predictive of attacks against MNCs? Our model sheds some light on this particular type of political violence and what governments and MNCs can do to limit it. 
Our findings suggest that neither behavioral measures of MNC activity nor overall levels of FDI are valuable predictors of terrorist attacks against MNCs. Rather, the most important predictors are country and regional lags of terrorism against MNCs, followed by four exogenous factors: GDP per capita, the percentage of population that is discriminated against, the intensity of any civil conflict, and a regional indicator for the Middle East and North Africa. Among the absent predictors is regime type, which has been shown to be a statistically significant covariate in models of transnational terrorism. Overall, this suggests that risks to MNCs at the country-year level of analysis are largely structural.

\subsection{Terrorist Attacks Against MNCs}

To investigate when MNCs are targets of terrorist violence, we use a count of the number of terrorist attacks against MNCs in a given country-year. We draw these data from the Global Terrorism Database (GTD), a widely used database that documents terrorist attacks from 1970 to 2017 (START, 2016). GTD's principle advantage is that it provides consistent and efficiently organized information on the targets of terrorism, including MNCs. However, the GTD also includes events that reflect terrorist tactics against enemy combatants in civil conflicts, thereby conflating terrorist events and other acts of political violence. It also conflates transnational and domestic terrorist attacks, the latter of which are much more common.

The data we use are a subset of transnational terrorist attacks identified by the procedure described in Enders et al. (2011). Their approach separates out attacks where the "victims, targets, supporters, or perpetrators... concern more than a single country" (p. 321). Important for our purposes, the GTD database includes variables for target types, which broadly classify the targets of any terrorist attack into several categories including businesses, governments, and police. The "business" category includes attacks against "individuals or organizations engaged in commercial or mercantile activity as a means of livelihood" (START, 2016). That category is subdivided into more specific types of targets, one of which is MNCs. Other categories include restaurants, factories, and hotels. After the previously mentioned refinements to the data, we select attacks against MNCs to obtain a total sample of 592 cases.

Even a cursory review of the data suggests that this subcategory is problematic. First, some of the other "business" subcategories can easily be, and sometimes are, subsidiaries of MNCs. In general, the subcategories seem not to be mutually exclusive. Second, some of the other, non-business target types can also be multinationals. One frequent target is foreign airlines, most 


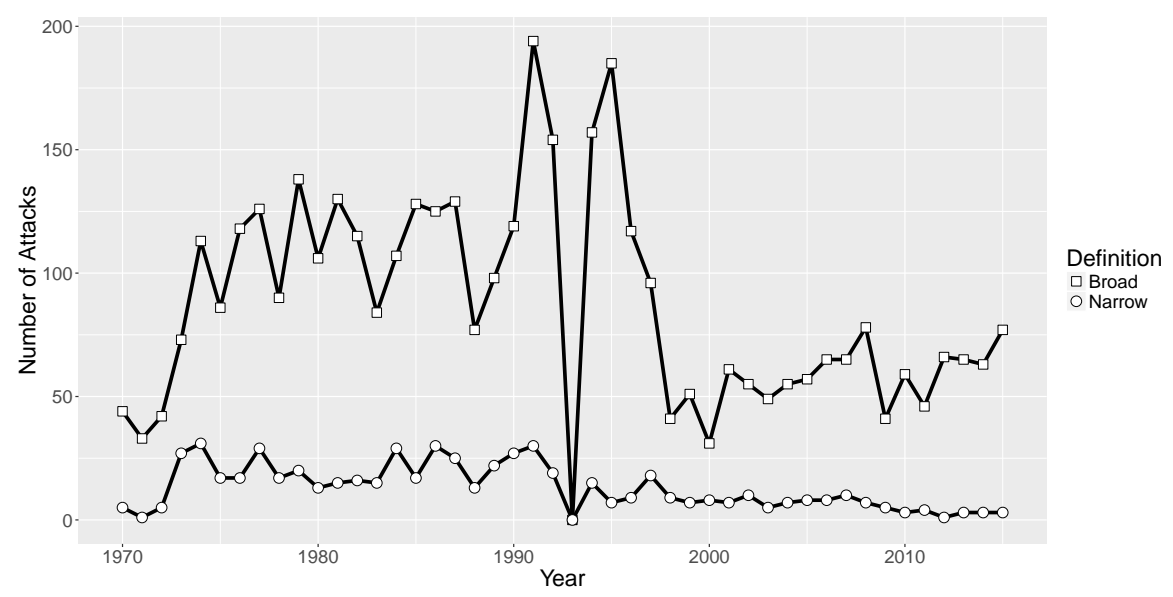

Figure 2: Terrorist Attacks Against MNC Targets

of which qualify as MNCs. Fortunately, each terrorist attack in the GTD database is coded as having up to three targets, so we include all cases that fall into the narrower MNC subcategory of business (att_narrow) as well as a broader set of events that meet our definition of transnational terrorism above and that involve corporations (att_broad). The latter sample includes an additional 4085 cases. Further refinement of the larger group is necessary, but will require substantial (and probably manual) combing of the data. In our statistical tests that follow, we therefore consider both the narrower "multinational corporation" set of events and the broader "business" set of events, aggregated by country-year.

Figure 2 depicts both the broader and narrower event counts over time. The line with squared points shows the count using the broader definition. It reflects a higher annual number of attacks from 1974 through 1998, but with recent increases since about 2009. The line with circular points reflects the narrower definition and shows higher numbers of attacks from the mid-1970s through the early 1990s, with a declining trend afterward. In general, our two separate indicators show fewer attacks in the last two decades than in earlier time periods, which is curious given the aforementioned concerns among businesses about such attacks, which appear to have increased in recent years.

\subsection{Measures of MNC Activity}

Firms may be targeted because of their own actions or the actions of other firms. We explore this possibility by creating measures for overall behavior 
of MNCs using indicators derived from the Integrated Crisis Early Warning System (ICEWS) database, which utilizes an automated event coding of news archives (Boschee et al., 2015; O'brien, 2010). The ICEWS data extend back to 1995 and are regularly updated on Harvard's Dataverse. ${ }^{8}$ ICEWS events have been used in predictive models of civil conflict (Chiba and Gleditsch, 2017; D'Orazio and Yonamine, 2015; Bagozzi, 2015), irregular leadership change (Ward and Beger, 2017; Beger et al., 2014), and elsewhere.

As with the GTD, identifying cases with MNCs is neither simple nor direct. ICEWS events are comprised of several attributes, including an event type coded using the CAMEO event ontology (Schrodt, 2012), a date, location, source actor and target actor. To identify MNC-related events, we focus on the actor variables. In addition to the name of the actor, ICEWS includes a field for source and target sectors. ${ }^{9}$ This field is optional, so not every actor must be associated with a sector, but one of the values used is "Multinational Corporations." Other sector fields include "Media," "Legal," and "Government." Usually, more than one sector is identified, so we first include all ICEWS events from 1995 to 2014 that contain "Multinational Corporation" in the source or target sector, leaving 11,807 events.

ICEWS also includes the name of the actor, and upon closer inspection we found that many events recorded by ICEWS contain actors that we believe should be coded as MNCs but are not identified as such. Further, some events labeled as "Multinational Corporation" in the sector appear to be incorrect. Therefore, we construct a verified list of MNC names that we matched with ICEWS actor names to subset MNC-related events. We begin with all MNCs in the Forbes Fortune 500 dating back to 1995. We combine this with a set of MNC parent and subsidiaries identified by Orbis. Then, we did a fuzzy match of these MNC names to the actor names in ICEWS to produce a candidate list MNCs for verification. For the fuzzy match, we shaped the MNC names to reflect the simpler coding that exists in ICEWS; for example we stripped "co." and "inc" from the end of the MNC list. Next, we manually verified all matched names to ensure that only MNCs were being included. For example, this manual verification removed "hong kong" and "united nations" from the list of MNCs. After this, we were left with a final list of 413 MNCs. We subset the ICEWS data using this verified set of MNCs and the ICEWS source and target actor names to identify a total of 34,886 MNC-related events, an increase of about three times over the approach using only ICEWS sector.

MNC-related events are plotted in Figure 3. The top panel shows the total count of events per year. We see a similar trend in MNC-related events when we use the ICEWS Sector and when we match by our list of MNC-verified

\footnotetext{
${ }^{8}$ Data are available at: https://dataverse.harvard.edu/dataverse/icews.

${ }^{9}$ Note the departure of this use of the word "sector" from its typical use in economics.
} 

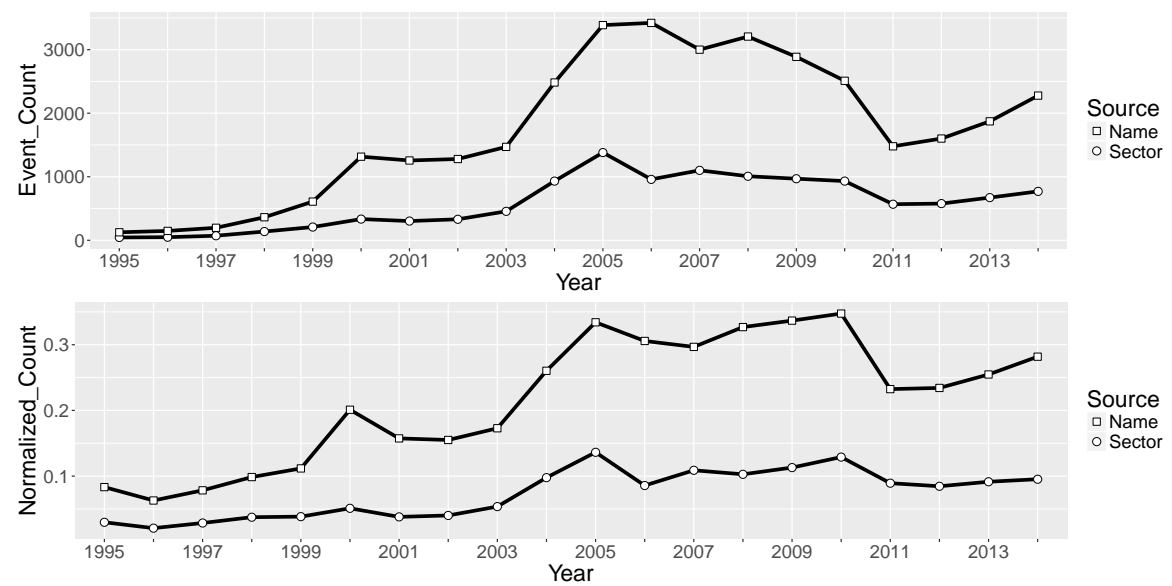

Figure 3: ICEWS MNC-Related Events

names, which we take as evidence that the ICEWS sector coding undercounts events, but does not drastically misrepresent the trend at the macro level. One important feature to note in the top panel is the overall increase in the number of events from the mid-1990s to the mid-2000s. This change in the raw count of events could be due to increased MNC activity or it could be because of the expansion of the ICEWS collection. For example, in 1995 ICEWS contains 151,310 events, while some years in the mid-2000s contain over 1 million events. To explore this further, we normalized the events to reflect the MNC-related events as a percent of the total events recorded by ICEWS in a given year. This is shown in the bottom panel. Generally, the trends are consistent, providing evidence that the increase over time is due to $\mathrm{MNC}$ activity and not necessarily the ICEWS expansion. In further tests, we use the raw count of events.

We use the ICEWS data to build indicators reflecting overall MNC behaviors in a country-year. For every ICEWS event that involves an MNC, we identify the type as one of material conflict (categories 14-20), material cooperation (categories 6-8), verbal conflict (categories 9-13), and verbal cooperation (categories 3-5) (Schrodt, 2012). ${ }^{10}$ We further distinguish whether the MNC is the source or target, which provides a total of eight event count measures. If an MNC is both source and target, then the event is counted for both the source and target quad class variables. The resulting data thus reflect levels of interactions between MNCs and other actors, including but not limited to host country governments. Finally, we constructed an additional variable that

\footnotetext{
${ }^{10}$ Categories 1 and 2, which total 10,557 observations, have been dropped because they are particularly noisy.
} 
is the logged sum of these eight measures. Since ICEWS events are extracted from news reports, this measure is intended to assess the overall visibility of MNCs in a country-year.

Concerns have been raised about the validity of automated event coded data. For example, Wang et al. (2016) find that ICEWS and three other event datasets do not produce similar data even though they use comparable coding rules. They also find that these databases record high levels of duplicate events. Among other concerns, Beieler et al. (2016) discuss the transparency of the automated coders, which is perhaps a concern since the ICEWS coder is not open-source. Nonetheless, ICEWS reflects a sustained, well-funded effort to produce high quality, automated event data with global coverage. We feel that is the best available data to use for an initial attempt to identify MNCrelated determinants of terrorism. Furthermore, these data are intended for use in forecasting models and prediction more generally, which is how we use them here.

\subsubsection{FDI-Based Measures}

FDI-based measures are commonly used to measure MNC activity (Zhu, 2017; Pinto and Zhu, 2016; Kwok and Tadesse, 2006). Here, we use inward FDI stocks $(f d i)$ to proxy for the broad range of economic activity associated with MNCs. We add FDI per capita $\left(f d i \_p c\right)$ to normalize MNC activity, and also construct a measure of the state's standard deviation from the annual, regional average of FDI per capita $\left(z_{-} f d i\right)$. Regions are defined using the World Bank Development indicators. This z-score measure captures the degree to which a state has higher or lower than expected FDI. Data on FDI come from the United Nations conference on Trade and Development (UNCTADSTAT, 2019).

These three FDI measures capture both the overall MNC activity in a state as well as perceptions of MNC activity. For example, the same amount of FDI in different size states may be perceived differently by groups operating in those areas; this is represented better by $f d i \_p c$ than $f d i$. Furthermore, a group's perception of foreign investments may be influenced by investments in nearby states; this is captured with $z_{-} f d i$. To the extent that FDI does influence a group's strategic calculus, we expect these three variables can capture the impact. 


\subsection{An Initial Benchmark Model}

To our knowledge, nobody has directly modeled terrorist attacks against MNCs. Therefore, we begin with an exploration of the model of transnational terrorism in Gaibulloev et al. (2017) as an initial benchmark. They focus primarily on the nonlinear relationship between regime type and transnational terrorism, and they find that transnational terrorist attacks are highest in unconsolidated democracies. While the purpose of our study is to forecast, we begin with this model for a few reasons. First, they use the GTD and focus on incidents of transnational terrorism, which includes attacks against MNCs. Second, they use a large set of independent variables based on the terrorism literature, including Savun and Phillips (2009), Wade and Reiter (2007), and Enders et al. (2016). This expanded set of theoretically relevant variables should provide leverage for a forecasting model. Third, although they use five-year periods rather than annual data, their focus on the country as the unit of observation means their results are reasonably comparable to our country-year analysis.

The variables in the benchmark model include regime type (polity), which is the 21-point Polity measure rescaled to range from 0 to 1 , along with its square (polity_sq) (Marshall et al., 2016). Also from the Polity database is the measure of regime durability (durability), which accounts for how long the regime has existed. The natural logs of GDP per capita $\left(l n \_g d p \_p c\right)$ and population ( $\left.l n \_p o p\right)$ are from the World Bank's World Development Indicators. Following Savun and Phillips (2009), the benchmark includes whether the host state has an alliance with the United States (us_ally) and whether it is currently involved in an international crisis (intl_crisis) (Gibler, 2008; Brecher et al., 2016). The intensity of civil wars (civil_war) accounts for local security environment which may make terrorism more likely (Marshall, 2016). Indices measuring a country's relative economic (econ_glob) and political (pol_glob) global integration are based on Dreher (2006) and Dreher et al. (2008). The discriminated population percentage (disc_pop) is from the Ethnic Power Relations data (Wimmer et al., 2009). Finally, regional dummies are coded for Africa (excluding North Africa), the Americas, Middle East and North Africa, and Asia. Each of these variables are detailed in (Gaibulloev et al., 2017, 504-506). From their analysis, we excluded the foreign interventions and national capabilities variables, as neither of these are statistically significant in any of their models at the $p<.05$ level.

Model GPS in Table 1 shows the results from the pooled negative binomial model of transnational terrorist attacks in (Gaibulloev et al., 2017, 509). This is not a replication of their model at the country year level, but rather the exact results of their preferred model. Using the data described above, we replicate this model using the broad and narrow measures of terrorist attacks 
against MNCs. These two models show a high degree of consistency between MNC attacks and the general transnational attacks in the GPS model, especially for the MNC-Broad model. For the MNC-Broad model, their key finding with respect to regime-type is replicated in terms of sign and statistical significance. For the MNC-Narrow model, the square of Polity is negative but not statistically significant. The coefficient for the log of population, US alliance, civil war intensity, and the Africa and Asia dummies are all consistent across the three models.

One surprising finding that comes from this analysis is that the coefficient for regime durability goes from positive and statistically significant to negative and statistically significant. Models 2 and 3 show that longstanding regimes suffer fewer attacks against MNCs, while the GPS models suggests that durability is associated with an increase in terrorist attacks. This may be because established governments are more attractive targets, and symbolic in their own right as they may have more established relationships with other countries. As a result, terrorists may target the government instead of MNCs. Or, it may be that established regimes are capable to provide additional security for MNCs, making them harder targets. Zhu (2017) shows that investment by MNCs are associated with increases in local corruption, and additional security may be part of that deal only when the regimes are actually capable of providing such security. Alternatively, terrorists could strategically target MNCs as a result of their inner-dealings with long-standing regimes. Future research should explore this empirical finding in more detail.

The results are quite similar to the Gaibulloev et al. (2017) model of transnational terrorism, so terrorist organizations may have a similar underlying logic in deciding to attack MNC or other targets. We take this as sufficient evidence to move forward with this as our benchmark model. However, this does not necessarily mean that this is a good forecasting model of attacks against MNCs. Furthermore, this model does not include any measures of MNC behaviors, so it is unknown if MNC activity has an impact. These questions are explored next.

\subsection{Forecasting MNC Terrorism}

In the models that follow, we forecast terrorist attacks against MNCs for time $t+1$. The initial training data span 1995 to 2006 . The initial testing data cover 2007 to 2010, which includes attacks against MNCs in 2011 as the target. For this analysis of attacks against MNCs, we opted to use data until 2011 for a more direct comparison to other, comparable models of terrorism, namely Gaibulloev et al. (2017) and Gassebner and Luechinger (2011), and to some extent Gelpi and Avdan (2018). After excluding dates outside this range and 
Table 1: Terrorist Attacks Against MNCs

\begin{tabular}{|c|c|c|c|}
\hline & \multicolumn{3}{|c|}{ Dependent variable: GTD Incidents } \\
\hline & $\begin{array}{c}\text { Transnational } \\
\text { GPS }\end{array}$ & $\begin{array}{c}\text { MNC-Broad } \\
(1) \\
\end{array}$ & $\begin{array}{c}\text { MNC-Narrow } \\
(2) \\
\end{array}$ \\
\hline polity & $\begin{array}{l}9.166^{* *} \\
(1.513)\end{array}$ & $\begin{array}{l}5.426^{* *} \\
(0.821)\end{array}$ & $\begin{array}{l}4.136^{*} \\
(1.746)\end{array}$ \\
\hline polity_sq & $\begin{array}{c}-7.636^{* *} \\
(1.330)\end{array}$ & $\begin{array}{c}-4.102^{* *} \\
(0.766)\end{array}$ & $\begin{array}{l}-3.109 \\
(1.594)\end{array}$ \\
\hline us_ally & $\begin{array}{l}1.167^{* *} \\
(0.277)\end{array}$ & $\begin{array}{l}0.509^{* *} \\
(0.127)\end{array}$ & $\begin{array}{l}0.826^{* *} \\
(0.251)\end{array}$ \\
\hline intl_crisis & $\begin{array}{l}0.810^{* *} \\
(0.198)\end{array}$ & $\begin{array}{l}0.347^{*} \\
(0.154)\end{array}$ & $\begin{array}{l}-0.367 \\
(0.338)\end{array}$ \\
\hline durability & $\begin{array}{l}0.007^{*} \\
(0.003)\end{array}$ & $\begin{array}{c}-0.008^{* *} \\
(0.002)\end{array}$ & $\begin{array}{c}-0.022^{* *} \\
(0.004)\end{array}$ \\
\hline civil_war & $\begin{array}{l}0.377^{* *} \\
(0.077)\end{array}$ & $\begin{array}{l}0.390^{* *} \\
(0.038)\end{array}$ & $\begin{array}{l}0.364^{* *} \\
(0.071)\end{array}$ \\
\hline disc_pop & $\begin{array}{l}1.906^{* *} \\
(0.681)\end{array}$ & $\begin{array}{l}1.952^{* *} \\
(0.325)\end{array}$ & $\begin{array}{l}1.989^{* *} \\
(0.724)\end{array}$ \\
\hline$l n \_g d p \_p c$ & $\begin{array}{c}0.130 \\
(0.114)\end{array}$ & $\begin{array}{l}0.388^{* *} \\
(0.056)\end{array}$ & $\begin{array}{c}0.359^{* *} \\
(0.114)\end{array}$ \\
\hline$l n \_p o p$ & $\begin{array}{l}0.628^{* *} \\
(0.108)\end{array}$ & $\begin{array}{l}0.748^{* *} \\
(0.043)\end{array}$ & $\begin{array}{c}0.935^{* *} \\
(0.085)\end{array}$ \\
\hline$e c o n \_g l o b$ & $\begin{array}{l}-0.012 \\
(0.007)\end{array}$ & $\begin{array}{l}-0.006 \\
(0.004)\end{array}$ & $\begin{array}{l}-0.006 \\
(0.007)\end{array}$ \\
\hline$p o l \_g l o b$ & $\begin{array}{l}-0.009 \\
(0.006)\end{array}$ & $\begin{array}{c}-0.013^{* *} \\
(0.003)\end{array}$ & $\begin{array}{l}-0.011 \\
(0.007)\end{array}$ \\
\hline Africa & $\begin{array}{c}-1.355^{* *} \\
(0.381)\end{array}$ & $\begin{array}{c}-1.158^{* *} \\
(0.191)\end{array}$ & $\begin{array}{c}-1.947^{* *} \\
(0.423)\end{array}$ \\
\hline Americas & $\begin{array}{l}-0.402 \\
(0.300)\end{array}$ & $\begin{array}{l}-0.095 \\
(0.143)\end{array}$ & $\begin{array}{l}-0.156 \\
(0.271)\end{array}$ \\
\hline Asia & $\begin{array}{c}-1.231^{* *} \\
(0.336)\end{array}$ & $\begin{array}{c}-1.612^{* *} \\
(0.185)\end{array}$ & $\begin{array}{c}-2.445^{* *} \\
(0.373)\end{array}$ \\
\hline$M E N A$ & $\begin{array}{c}0.018 \\
(0.385)\end{array}$ & $\begin{array}{c}0.004 \\
(0.167)\end{array}$ & $\begin{array}{c}-1.387^{* *} \\
(0.354)\end{array}$ \\
\hline Constant & & $\begin{array}{c}-16.434^{* *} \\
(0.811) \\
\end{array}$ & $\begin{array}{c}-20.495^{* *} \\
(1.630)\end{array}$ \\
\hline N Obs. & 892 & 4,481 & 4,481 \\
\hline
\end{tabular}

Note:

Standard errors in parentheses. ${ }^{*} \mathrm{p}<0.05 ;{ }^{* *} \mathrm{p}<0.01$ 
removing observations with missingness, we are left with 2,064 observations for our analysis.

We use the expanding window method to assess out-of-sample performance (Hyndman and Athanasopoulos, 2018; Mueller and Rauh, 2018). This means the initial model is trained using all data from 1995 to 2006 and forecasts for 2007. Then, a new model is trained using all data from 1995 to 2007, and forecasts for 2008. This process iterates until forecasts for all years are obtained. Root mean squared error (RMSE), the performance metric used here, is then computed using forecasts from 2007 to 2010. "Better models" thus have lower RMSE.

We use the random forest as our learning algorithm (Hastie et al., 2011; Breiman, 2001). Montgomery and Olivella (2018) describe this algorithm with detailed applications for political science. Arel-Bundock (2017) also provides a general description of the algorithm, and uses it to predict FDI flows. The general idea underlying the random forest is to learn a set of data-based decision rules that predict well out-of-sample. For example, in our country-year data where the dependent variable is the number of terrorist attacks against MNCs, a decision rule might be if GDP per capita is greater than the mean of GDP per capita, predict 1. Through repeated sampling of data and variables, the algorithm identifies many combinations of decision rules and uses those that are expected to predict well out-of-sample.

Random forests have been used and shown to be effective in several conflict forecasting applications (Hegre et al., 2019; Jones and Lupu, 2018; Colaresi and Mahmood, 2017; Hill and Jones, 2014). In addition to forecasting well, the algorithm can detect non-linear relationships in the data, and non-linearities are a well-known feature in conflict models (Muchlinski et al., 2016; Lagazio and Marwala, 2006; Beck et al., 2000). This should enable us to identify any relationship between terrorist acts against MNCs and MNC actions, should they exist. Since the dependent variable is a count of the number of terrorist attacks against MNCs, we use random forest regression.

We choose the random forest because it can detect non-linear relationships and has been successful in other conflict forecasting applications. We opt against the negative binomial regression, which is used in Gassebner and Luechinger (2011) and Gaibulloev et al. (2017), because of difficulties handling a lagged dependent variable (Fogarty and Monogan III, 2014; Brandt and Williams, 2001). The poisson autoregressive model specified in Brandt and Williams (2001) and applied to terrorism time series in Brandt and Sandler (2009) is an alternative that can handle lags of the dependent variable. However, given the structure of our data with relatively many states and few years, and the relatively large number of potential predictors, this model is not ideal for our purposes either. Thus, given the strengths of random forest and the weakness 
of other methods that have been used to model terrorist attacks, we select random forest.

\subsubsection{Benchmark With Additions}

We first compute the RMSE using all variables in the benchmark model and the out-of-sample procedure described above. Then, we add the one year lags to the model, which are the number of MNC attacks in country (attacks), and the sum of all MNC attacks in the region (attacks_reg). Next, we add the three FDI-based measured, which include inward FDI stocks $(f d i)$, FDI per capita ( $\left.f d i_{\_} p c\right)$, and the z-score of FDI to measure deviation from the regional mean $\left(z_{-} f d i\right)$. In the fourth set of variables we include the eight ICEWSderived measures of MNC-related events ( svcp, smcp, svcf, smcf, tvcp, tmcp, $t c v f, t m c f)$. Finally, these eight measures are replaced with a single ICEWSderived measure, the logged sum of MNC-related events (log_events).

In these tests, a new series of random forest models, each with 250 trees, is learned for each of the 500 bootstrapped samples. That is, for each variable set and each bootstrapped sample, we train four models, one to forecast each year from 2007-2010. RMSE is then computed using the predicted values for the out-of-sample training data.

Figure 4 shows the out-of-sample performance for these five variables sets. While there is a slight improvement in performance when the lags are added, none of the additional variables improve substantially on the performance of the benchmark model. This finding is the same for the MNC-Broad and MNC-Narrow dependent variables.

Figure 4 suggests that MNC behaviors do not have much of an impact on the likelihood MNCs are targeted. However, it might be the case that we can forecast with comparable or better performance with many fewer variables. That is, the story might be simpler than that which is suggested by the benchmark. We proceed to identify a more parsimonious model with comparable or better out-of-sample performance. We move forward with a focus on the MNC-Broad attacks due to the performance issues with the MNC-Narrow models associated with the fact that there are just 16 incidents across 12 country-years in the test data. Thus, we would not put much stock in those analysis. In contrast, there are 153 incidents across 65 country-years in the test data for the MNC-Broad. 

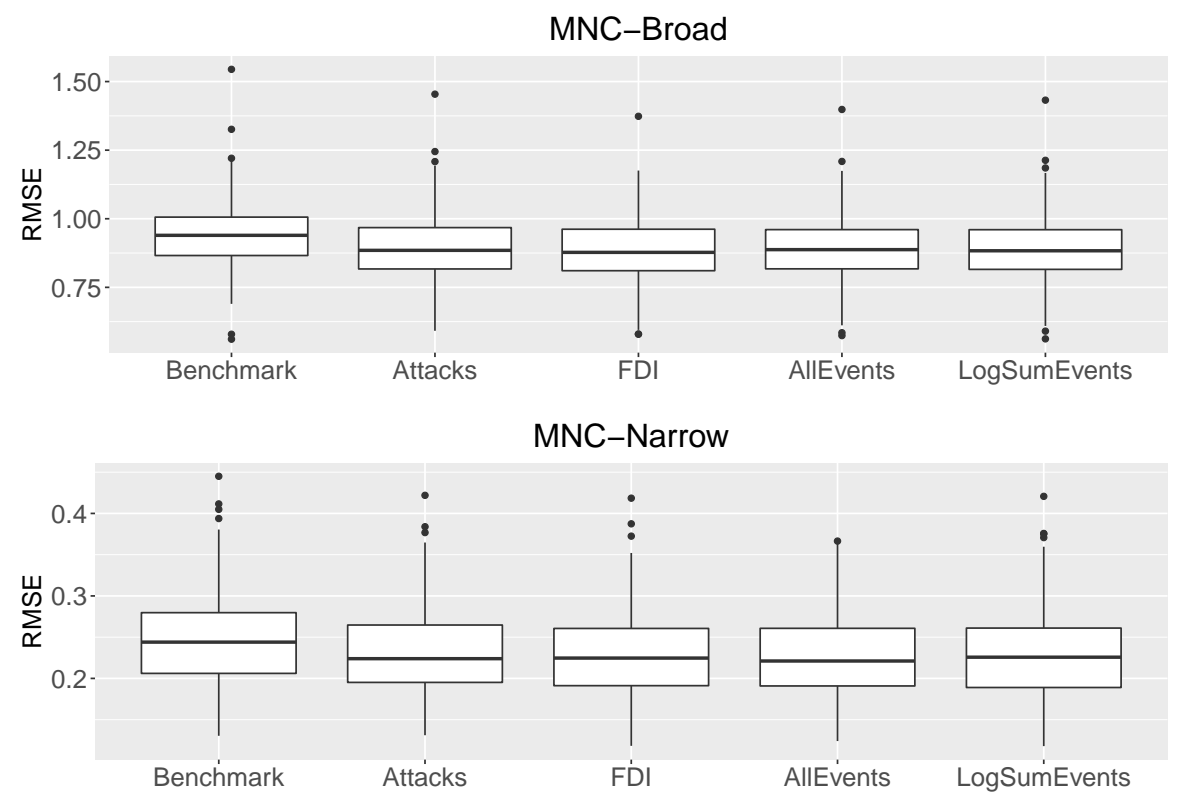

Figure 4: Performance For Five Variable Sets

\subsubsection{Forward and Backward Stepwise Selection}

To identify a model that performs well with potentially fewer variables, we use both forward and backward stepwise variable selection. In forward stepwise, we iterate through our set of 29 predictors to find the one that produces a model with the lowest RMSE. Keeping this variable in all future models, we iterate through the remaining 28 variables and keep the best performing two variable model. We repeat this process through the entire set of 29 variables. In backward stepwise, in the first iteration we begin with all 29 variables, drop one at a time and compute the RMSE. In the second iteration, we remove the variable excluded from the model that performed best, and then repeat the procedure. In both cases, we obtain an ordered list of variables based on their contribution to model performance.

We use this approach in part because the selection is the result of out-ofsample forecasts using models trained on incrementally more data over iterations in the expanding window. This helps to prevent overfitting, which is a major concern with a model as flexible as the random forest, and is likely a real concern given the number of terrorist attacks against MNCs is low.

Using the variable importance ordering produced with the forward and back- 


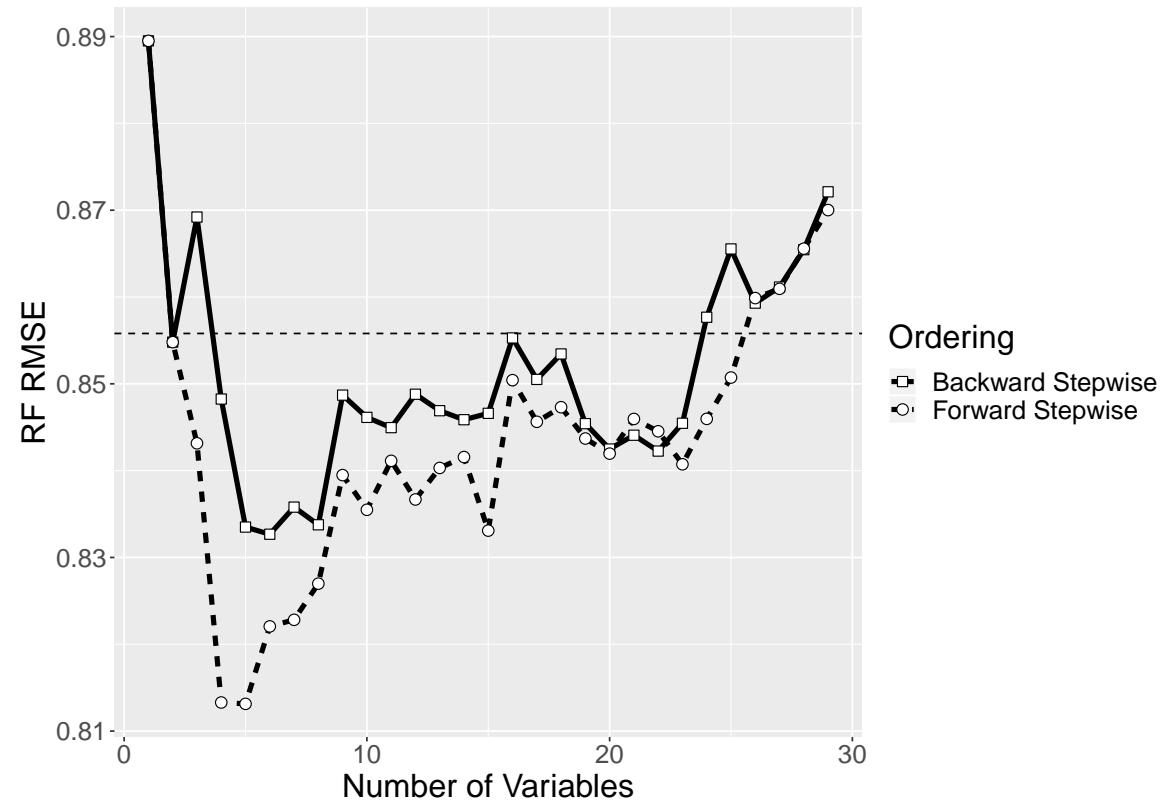

Figure 5: Performance for MNC-Broad Models

ward stepwise approaches, we then compute the out-of-sample RMSE incrementally, by adding one new variable at a time. This performance is shown in Figure 5 for both orderings. The dashed line is a baseline that represents the performance of the best-performing model from the previous section on the original, non-bootstrapped data. The solid line with squared points is the backward stepwise, and the dashed line with circular points is the forward stepwise ordering.

One important finding from Figure 5 is that just two variables are needed to obtain comparable performance to the baseline. In both orderings, attacks and attacks_reg are selected first and second, respectively. Clearly, these variables are crucial for any forecasting model of attacks on MNCs. The value of these variables was indicated in the tests reported in Figure 4, but is more obvious here. This finding is consistent with evidence in other conflict forecasting models that point to the importance of dependencies in conflict data (Cranmer and Desmarais, 2017; Weidmann and Ward, 2010), including Gelpi and Avdan (2018) who predict transnational terrorism.

Second, in each case the model out-performs the benchmark, but begins to overfit quickly as more variables are added. For the backward stepwise, performance levels off at five variables and begins to decrease at nine. For the 
forward stepwise, performance levels off at four and begins to decrease at six. Thus, to assess the risk of terrorist attacks against MNCs, many fewer variables are needed than the benchmark would suggest.

We list the top ten variables by importance in Table 2. Four of the top five in each ordering are the same: attacks, attacks_reg, MENA, and civil_war. disc_pop is included in the forward stepwise, while $l o g \_g d p \_p c$ is in the backward stepwise. While some variables that measure $\overline{M N C}$ actions do appear in the top ten list, none improve performance in any substantial way.

Gaibulloev and Sandler (2019) describe globalization, poverty, and democracy as three primary causes of terrorism that were put forth following the attacks of September 11, 2001. In their extreme bounds analysis on the causes of terrorism, Gassebner and Luechinger (2011) identify GDP per capita, population, and regime type as "commonly accepted explanatory variables" (p247). Each of these variable are in our initial set of 29 predictors, but only GDP per capita emerges as a valuable predictor of attacks targeting MNCs. Seeing as Gaibulloev and Sandler (2019) state "there is little convincing evidence supporting globalization as a cause of transnational terrorism," our findings are consistent in this regard (p313). The remaining two core variables associated with terrorism - democracy and population - are the ones where attacks on MNCs may diverge from transnational attacks more generally.

With respect to MNC activity, the lack of impact may be because the presence of MNCs in the news, and the behavioral events that are described, are not part of the strategic calculus of terrorist groups. For example, it might be the case that whether a group decides to attack an MNC has nothing to do with the actions of the MNC, but rather just the symbolic nature of the MNC. This possibility is aligned with the theoretical expectations of Marineau et al. (2018), who argue that more symbolic locations are likely to be targeted.

Overall, these tests show that the benchmark model is overfit, with only five or six variables necessary to forecast attacks against MNCs. They also show that MNC activity, whether the ICEWS-derived behavioral measures or the FDI-based measures, are not valuable predictors of terrorist attacks on MNCs.

\subsection{Exploring Theoretical Foundations of the Forecasting Model}

The above tests have been designed to identify a parsimonious model that forecasts terrorists attacks against MNCs. Based on this analysis, we select six variables that are theoretically relevant and valuable predictors: attacks, attacks_reg, MENA, civil_war, disc_pop, and $l n \_g d p \_p c$. To explore the relationship between attacks on MNCs and these predictors, we estimate a model using all data from 1995-2010 and construct a partial dependence plot, 
Table 2: Variable Importance Ordering

\begin{tabular}{r|ll} 
& Forward & Backward \\
\hline 1 & attacks & attacks \\
2 & attacks_reg & attacks_reg \\
3 & disc_pop & MENA_ \\
4 & MENA & civil_war \\
5 & civil_war & ln_gdp_pc \\
\cline { 2 - 3 } 6 & polity & tmcp \\
7 & ASIA & tmcf \\
8 & $z \_f d i \_p c$ & us_ally \\
9 & intl_crisis & svcf \\
10 & smcp & tvcf \\
\hline
\end{tabular}

shown in Figure 6. This figure also includes a rug plot to show the distribution of the data, which helps to avoid drawing strong inferences based on few data points.

Partial dependence plots are used to assess the importance of a variable for predicting the target across different values of that variable (Hastie et al., 2011). Empirically, the plot is drawn by generating predictions for each observed value of a given variable using all unique combinations of covariate values, and then taking the mean of each set of predictions. In a sense, they are like marginal effects plots but without any implicit claim to causal relationships.

Figure 6 shows a non-linear relationship for $l n \_g d p \_p c$, consistent with Enders et al. (2016). The $l n \_g d p \_p c$ curve appears to have three distinct peaks - at very low values, very high values, and values concentrated in the middle. The expected increase in terrorist attacks in the middle is also consistent with the findings in Enders et al. (2016), who identify the relationship between GDP per capita and transnational terrorism to be generally of an inverted-U shape. However, the peaks at very low and very high values of $l n \_g d p \_p c$ may be specific to attacks against MNCs, and require further research to understand better.

The curve for disc_pop is somewhat logarithmic and suggests a small discriminated population is sufficient to increase the likelihood of attacks. This variable has been shown to be a strong predictor of civil wars, for example in Colaresi and Mahmood (2017), Buhaug et al. (2014), Ward et al. (2013), and Chiba and Gleditsch (2017). As civil_war is also selected, it may be that discriminated populations have an impact on terrorist attacks against MNCs through their known influence on the likelihood of civil conflict. In a related line of reasoning, Savun and Phillips (2009) hypothesize that politi- 
cal and economic discrimination increase the likelihood of domestic terrorism (p886). While domestic terrorism events are often conflated with civil conflict events, Enders et al. (2011) also show that domestic terrorism drives transnational terrorism which includes attacks against MNCs. Thus, it may be that disc_pop has an indirect, but consequential relationship with attacks on MNCs.

With respect to attacks and attacks_reg, despite the sort of stepwise relationship shown in Figure 6, the relationship is linear for the bulk of the data as indicated by the rug plot. In a simple sense, this shows that as past in-state and in-region attacks go up, so does the likelihood of future attacks on MNCs. This dependency brings up the question, what drove the initial attacks to begin with? One explanation consistent with our findings here is that the grievances of discriminated populations can lead to increases in local conflict, in the form of both civil conflict and domestic terrorism, which in turn drive transnational terrorism, including attacks on MNCs. The formation of Al Qaeda in Afghanistan in the 1980s, and its transformation into a transnational terrorist organization, is consistent with this explanation.

It is important to note that MNCs are one target out of potentially many targets. In addition to the country-level factors analyzed here, there are many group-level factors that influence target selection. For example, Abrahms and Potter (2015) show that a lack of strong leadership, or a "leadership deficit," is associated with less selectivity and thus more attacks against civilians. It is unclear how such arguments relate to MNCs, however, since MNCs may be both civilian and symbolic of foreign interests. Asal and Hastings (2015) find that terrorist groups that launch maritime attacks are those with greater capabilities, which also presents incentives to do so. Future research should explore how group-level attributes, such as leadership and capabilities, affect the propensities and incentives to attack MNCs. It is likely that an understanding of the groups known to operate in a particular region, in addition to the country-level trends identified here, would help governments and MNCs quantify better the risks associated with their operations. It might also be the case that there is a relationship between group-level features and MNC behaviors, such that the behaviors of MNCs do matter. At our level of analysis, however, such a relationship is not discernible.

\section{Conclusion}

Where and why do terrorists attack MNCs? Answers to this question provide information for policy-makers in state governments, the political risk industry as they provide insurance for political violence, and MNCs broadly. We 

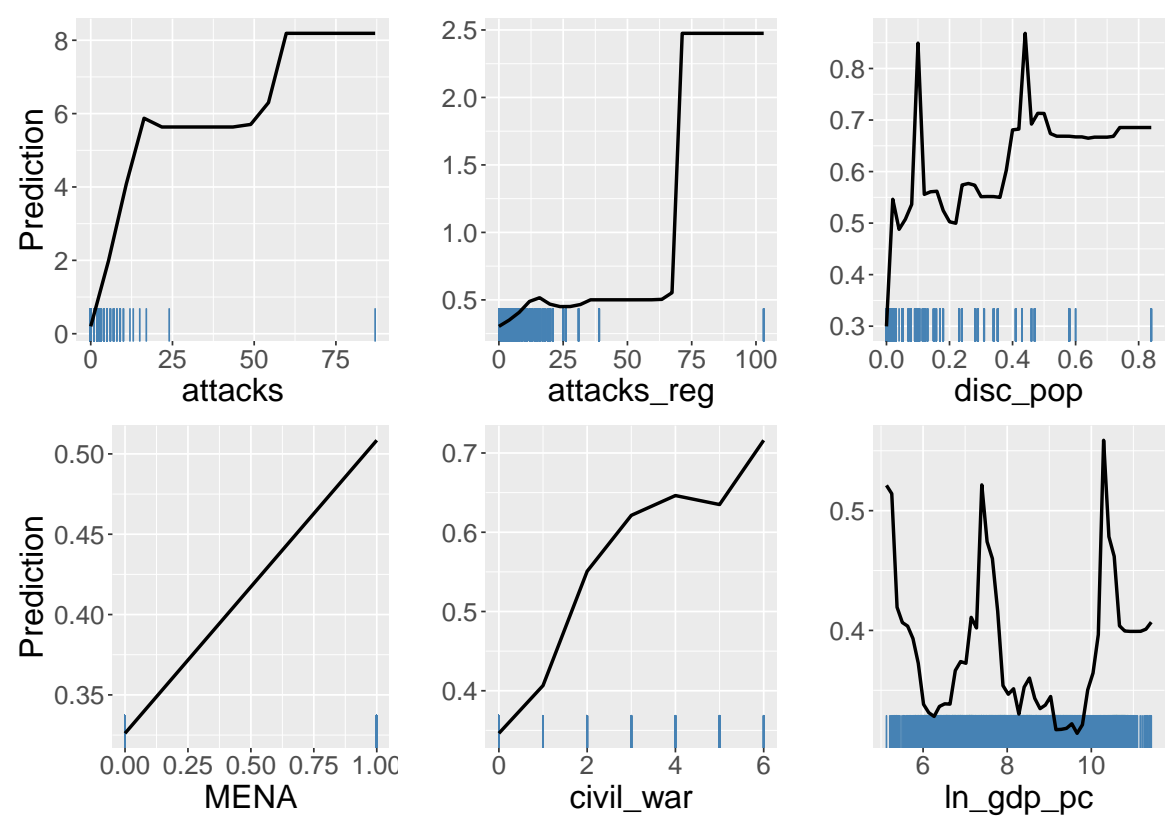

Figure 6: Partial Dependence Plots

discuss potential motivations, including MNC activity, and offer at least three contributions toward an answer.

First, we ask whether traditional models of transnational terrorism do well to forecast the subset of attacks against MNCs. Our evidence suggests that some of the same factors play a role, such as income, but other factors such as regime-type are less consequential. Furthermore, models of transnational terrorism tend to be more complex than what we find to be relevant for attacks against MNCs. Future research should explore the causes of terrorism against MNCs in more detail, and particularly at the firm and group levels of analysis.

One surprising finding from our work is that MNCs were targeted more in the 1970s than they are now, despite the rise in globalization of production and MNC activity around the world. Furthermore, we show very strong evidence that dependencies matter, which is to say that past attacks are the best predictors of future attacks. This presents an interesting question: dependencies matter in our sample from 1995-2011, yet there is a clear shift away from attacks against MNCs in earlier periods. Why? Future research should explore this question further.

Our second contribution is to examine whether MNC activities themselves 
drive terrorist attacks. We assess behavioral measures from the ICEWS database and economic activity using FDI. The evidence suggests these factors are not valuable predictors of terrorism against MNCs. While there are many potential reasons for this non-finding, one is that the country-year level of analysis obscures any relationship. Following Marineau et al. (2018), future research might disaggregate the analysis spatially, perhaps with event-level geocoding (Lee et al., 2018; Gunasekaran et al., 2018). With firm and group level data, one promising approach is to model interactions using sequence analysis methods (Casper and Wilson, 2015; D'Orazio and Yonamine, 2015). Substantive research has been conducted at this level, for example petroleum companies operating in Nigeria (Akporiaye, 2014) and mining operations in Africa (Christensen, 2019). We are therefore optimistic that future research at disaggregate levels can help to explain attacks against MNCs and the role of MNC behaviors.

Another possibility is that the automated event count data are too noisy due to the inattention to MNCs in the actor dictionaries. ICEWS and other event data projects such as those at the Cline Center at Illinois (Althaus et al., 2017; Nardulli et al., 2015) and UT Dallas Event Data (Solaimani et al., 2016; Kim et al., 2019) could focus efforts on including MNCs as actors, although this is no easy task - some firms intentionally name subsidiaries to promote opaque or non-existent ties to parent firms. We have helped to create a larger list of multinationals, using datasets and media lists that have already identified some of the relevant actors, and this effort could be incorporated into these or similar projects in the future. In addition to these expanded lists of MNCs, automated coding must make sure to include news sources that are more business-oriented.

Finally, we identify data on transnational attacks against MNCs and highlight some difficulties in using default measures in the GTD data. In particular, GTD fails to include some businesses that should qualify as MNCs. We therefore use a broader definition for MNC attacks, which likely includes some attacks against businesses that do not qualify as MNCs. Future work should further narrow this to the proper set of cases to improve our understanding of the risks firms incur when they conduct business abroad. 


\section{References}

Abadie, A. and J. Gardeazabal (2008), 'Terrorism and the World Economy'. European Economic Review 52(1), 1-27.

Abrahms, M. and P. B. Potter (2015), 'Explaining terrorism: Leadership deficits and militant group tactics'. International Organization 69(2), 311342 .

Aguirre, D. (2011), 'Corporate Liability for Economic, Social and Cultural Rights Revisited: The Failure of International Cooperation'. California Western International Law Journal 42, 123-148.

Akporiaye, A. (2014), 'Political Risk and Multinational Corporations: Case of Multinational Energy Corporations'. Ph.D. thesis, University of Texas at Dallas.

Althaus, S., J. Bajjalieh, J. F. Carter, B. Peyton, and D. A. Shalmon (2017), 'Cline Center Historical Phoenix Event Data. v.1.0.0.'. http://www.clinecenter.illinois.edu/data/event/phoenix/.

Anderton, C. H. and J. R. Carter (2001a), 'The Impact of War on Trade: An Interrupted Time-series Study'. Journal of Peace Research 38(4), 445-457.

Anderton, C. H. and J. R. Carter (2001b), 'On Disruption of Trade by War: A Reply to Barbieri \& Levy'. Journal of Peace Research 38(5), 625-628.

Arel-Bundock, V. (2017), 'The political determinants of foreign direct investment: A firm-level analysis'. International Interactions 43(3), 424-452.

Asal, V. and J. V. Hastings (2015), 'When terrorism goes to sea: Terrorist organizations and the move to maritime targets'. Terrorism and Political Violence 27(4), 722-740.

Bagozzi, B. E. (2015), 'Forecasting civil conflict with zero-inflated count models'. Civil Wars 17(1), 1-24.

Ballard, C. and G. Banks (2003), 'Resource wars: The anthropology of Mining'. Annual Review of Anthropology pp. 287-313.

Bandyopadhyay, S., T. Sandler, and J. Younas (2014), 'Foreign Direct Investment, Aid, and Terrorism'. Oxford Economic Papers 66(1), 25-50.

Barry, C. M. (2018), 'Peace and Conflict at Different Stages of the FDI Lifecycle'. Review of International Political Economy 25(2), 270-292. 
Beck, N., G. King, and L. Zeng (2000), 'Improving quantitative studies of international conflict: A conjecture'. American Political Science Review 94(1), 21-35.

Beger, A., C. L. Dorff, and M. D. Ward (2014), 'Ensemble Forecasting of Irregular Leadership Change'. Research 63 Politics 1(3), 2053168014557511.

Beieler, J., P. T. Brandt, A. Halterman, P. A. Schrodt, E. M. Simpson, and R. M. Alvarez (2016), 'Generating political event data in near real time'. Computational Social Science p. 98.

Berne Union, T. (2016), 'Berne Union Statistics, 2011-2015'. Accessed 27 September 2016.

Boschee, E., J. Lautenschlager, S. Shellman, and A. Shilliday (2015), 'ICEWS Dictionaries'.

Brandt, P. T. and T. Sandler (2009), 'Hostage taking: Understanding terrorism event dynamics'. Journal of Policy Modeling 31(5), 758-778.

Brandt, P. T. and J. T. Williams (2001), 'A Linear Poisson Autoregressive Model: The Poisson AR(p) Model'. Political Analysis 9(2), 164âĂŞ184.

Brecher, M., J. Wilkenfeld, K. Beardsley, P. James, and D. Quinn (2016), 'International Crisis Behavior Data Codebook, Version 11'.

Breiman, L. (2001), 'Random forests'. Machine learning 45(1), 5-32.

Brueckner, M., A. Durey, C. Pforr, and R. Mayes (2014), 'The Civic Virtue of Developmentalism: On the Mining Industry's Political Licence to Develop Western Australia'. Impact Assessment and Project Appraisal 32(4), 315326.

Buhaug, H., L.-E. Cederman, and K. S. Gleditsch (2014), 'Square pegs in round holes: Inequalities, grievances, and civil war'. International Studies Quarterly 58(2), 418-431.

Casper, G. and M. Wilson (2015), 'Using sequences to model crises'. Political Science Research and Methods 3(2), 381-397.

Chen, S. and P. Bouvain (2009), 'Is corporate responsibility converging? A comparison of corporate responsibility reporting in the USA, UK, Australia, and Germany'. Journal of Business Ethics 87(1), 299-317.

Chiba, D. and K. S. Gleditsch (2017), 'The shape of things to come? Expanding the inequality and grievance model for civil war forecasts with event data'. Journal of Peace Research 54(2), 275-297. 
Christensen, D. (2019), 'Concession Stands: How Mining Investments Incite Protest in Africa'. International Organization 73(1), 65-101.

Colaresi, M. and Z. Mahmood (2017), 'Do the robot: Lessons from machine learning to improve conflict forecasting'. Journal of Peace Research 54(2), $193-214$.

Collier, P. (1999), 'On the Economic Consequences of Civil War'. Oxford Economic Papers 51(1), 168-183.

Collier, P. and A. Hoeffler (2004), 'Greed and Grievance in Civil War'. Oxford economic papers 56(4), 563-595.

Cranmer, S. J. and B. A. Desmarais (2017), 'What can we learn from predictive modeling?'. Political Analysis 25(2), 145-166.

D'Orazio, V. and J. E. Yonamine (2015), 'Kickoff to conflict: A sequence analysis of intra-state conflict-preceding event structures'. PloS one 10(5), e0122472.

Dreher, A. (2006), 'Does Globalization Affect Growth? Evidence from a New Index of Globalization'. Applied Economics 38(10), 1091-1110.

Dreher, A., N. Gaston, and P. Martens (2008), 'Measuring Globalisation'. Gauging its Consequences Springer, New York.

Driffield, N., C. Jones, and J. Crotty (2013), 'International Business Research and Risky Investments, An Analysis of FDI in Conflict Zones'. International Business Review 22(1), 140-155.

Enders, W., G. A. Hoover, and T. Sandler (2016), 'The changing nonlinear relationship between income and terrorism'. Journal of Conflict Resolution 60(2), 195-225.

Enders, W., A. Sachsida, and T. Sandler (2006), 'The Impact of Transnational Terrorism on US Foreign Direct Investment'. Political Research Quarterly $\mathbf{5 9}(4), 517-531$.

Enders, W. and T. Sandler (1996), 'Terrorism and Foreign Direct Investment in Spain and Greece'. Kyklos 49(3), 331-352.

Enders, W., T. Sandler, and K. Gaibulloev (2011), 'Domestic Versus Transnational Terrorism: Data, Decomposition, and Dynamics'. Journal of Peace Research 48(3), 319-337.

Evuleocha, S. U. (2005), 'Managing indigenous relations: Corporate social responsibility and corporate communication in a new age of activism'. Corporate Communications: An International Journal 10(4), 328-340. 
Faran, M. (2014), 'An Impact Assessment of Expected Future Turmoil Risk on FDI: A Panel Data Analysis of Developing Countries'. The Lahore Journal of Economics 19(2), 101.

Filer, R. K. and D. Stanišić (2016), 'The Effect of Terrorist Incidents on Capital Flows'. Review of Development Economics 20(2), 502-513.

Fogarty, B. J. and J. E. Monogan III (2014), 'Modeling time-series count data: the unique challenges facing political communication studies'. Social science research 45, 73-88.

Fortna, V. P. (2015), 'Do Terrorists Win? Rebels' Use of Terrorism and Civil War Outcomes'. International Organization 69(03), 519-556.

Gaibulloev, K., J. A. Piazza, and T. Sandler (2017), 'Regime Types and Terrorism'. International Organization 71, 491-522.

Gaibulloev, K. and T. Sandler (2019), 'What we have learned about terrorism since 9/11'. Journal of Economic Literature 57(2), 275-328.

Gassebner, M. and S. Luechinger (2011), 'Lock, stock, and barrel: A comprehensive assessment of the determinants of terror'. Public Choice 149(3-4), 235.

Gelpi, C. and N. Avdan (2018), 'Democracies at risk? A forecasting analysis of regime type and the risk of terrorist attack'. Conflict management and peace science $\mathbf{3 5}(1)$, 18-42.

Gibler, D. M. (2008), International Military Alliances, 1648-2008. CQ Press.

Gunasekaran, A. K., M. B. Imani, L. Khan, C. Grant, P. T. Brandt, and J. S. Holmes (2018), 'SPERG: Scalable Political Event Report Geoparsing in Big Data'. In: 2018 IEEE International Conference on Intelligence and Security Informatics (ISI). pp. 187-192.

Hastie, T., R. Tibshirani, and J. Friedman (2011), The elements of statistical learning. Springer, 2nd edition.

Hegre, H., M. Allansson, M. Basedau, M. Colaresi, M. Croicu, H. Fjelde, F. Hoyles, L. Hultman, S. Högbladh, R. Jansen, et al. (2019), 'ViEWS: A political violence early-warning system'. Journal of Peace Research p. 0022343319823860 .

Henisz, W. J., S. Dorobantu, and L. J. Nartey (2014), 'Spinning Gold: The Financial Returns to Stakeholder Engagement'. Strategic Management Journal 35(12), 1727-1748. 
Hill, D. W. and Z. M. Jones (2014), 'An empirical evaluation of explanations for state repression'. American Political Science Review 108(3), 661-687.

Hyndman, R. J. and G. Athanasopoulos (2018), Forecasting: principles and practice. OTexts.

Idemudia, U. (2008), 'Conceptualising the CSR and Development Debate'. Journal of Corporate Citizenship 2008(29), 91-110.

Idemudia, U. (2010), 'Rethinking the Role of Corporate Social Responsibility in the Nigerian Oil Conflict: The Limits of CSR'. Journal of International Development 22(7), 833-845.

Jakobsen, J. (2010), 'Old Problems Remain, New Ones Crop Up: Political Risk in the 21st Century'. Business Horizons 53(5), 481-490.

Jenkins, B. M. (2006), 'The New Age of Terrorism'. Terrorism and Political Islam p. 25.

Jensen, N. M. and D. J. Young (2008), 'A Violent Future? Political Risk Insurance Markets and Violence Forecasts'. Journal of Conflict Resolution $\mathbf{5 2}(4), 527-547$.

Johnston, D. (2008), 'Lifting the Veil on Corporate Terrorism: The Use of the Criminal Code Terrorism Framework to Hold Multinational Corporations Accountable for Complicity in Human Rights Violations Abroad'. $U$. Toronto Fac. L. Rev. 66, 137.

Jones, Z. M. and Y. Lupu (2018), 'Is There More Violence in the Middle?'. American Journal of Political Science 62(3), 652-667.

Joshi, M. and J. M. Quinn (2018), 'Civil War Termination and Foreign Direct Investment, 1989-2012'. Conflict Management and Peace Science p. 0738894218778260 .

Kalyvas, S. N. (2006), The logic of violence in civil war. Cambridge University Press.

Kemp, D. (2010), 'Community relations in the global mining industry: Exploring the internal dimensions of externally orientated work'. Corporate Social Responsibility and Environmental Management 17(1), 1-14.

Kemp, D., J. R. Owen, N. Gotzmann, and C. J. Bond (2011), 'Just Relations and Company-Community Conflict in Mining'. Journal of Business Ethics 101(1), 93-109. 
Kim, H., V. D'Orazio, P. Brandt, J. Looper, S. Salam, L. Khan, and M. Shoemate (2019), 'UTDEventData: An R package to access political event data'. The Journal of Open Source Software 4, 1322.

Koubi, V. (2005), 'War and Economic Performance'. Journal of Peace Research 42(1), 67-82.

Kwok, C. C. and S. Tadesse (2006), 'The MNC as an agent of change for host-country institutions: FDI and corruption'. Journal of International Business Studies 37(6), 767-785.

Lagazio, M. and T. Marwala (2006), 'Assessing different bayesian neural network models for militarized interstate dispute: Outcomes and variable influences'. Social Science Computer Review 24(1), 119-131.

Le Billon, P. (2001), 'The Political Ecology of War: Natural Resources and Armed Conflicts'. Political geography 20(5), 561-584.

Lee, C.-y. (2017), 'Terrorism, Counterterrorism Aid, and Foreign Direct Investment'. Foreign Policy Analysis pp. fpa-12087.

Lee, S. J., H. Liu, and M. D. Ward (2018), 'Lost in Space: Geolocation in Event Data'. Political Science Research and Methods pp. 1-18.

Li, C., S. M. Murshed, and S. Tanna (2017), 'The Impact of Civil War on Foreign Direct Investment Flows to Developing Countries'. The Journal of International Trade \& Economic Development 26(4), 488-507.

Li, Q. (2006), 'Political Violence and Foreign Direct Investment'. Research in Global Strategic Management 12, 231-255.

Li, Q. and T. Vashchilko (2010), 'Dyadic Military Conflict, Security Alliances, and Bilateral FDI Flows'. Journal of International Business Studies 41(5), 765-782.

Lim, A. and K. Tsutsui (2012), 'Globalization and commitment in corporate social responsibility: Cross-national analyses of institutional and politicaleconomy effects'. American Sociological Review 77(1), 69-98.

Lompo, K. and J.-F. Trani (2013), 'Does Corporate Social Responsibility Contribute to Human Development in Developing Countries? Evidence from Nigeria'. Journal of Human Development and Capabilities 14(2), 241265.

Luo, Y. (2009), Political Risk and Country Risk in International Business: Concepts and Measures, pp. 740-764. Oxford, 2nd edition. 
Marano, V., A. Cuervo-Cazurra, and C. C. Kwok (2013), 'The Impact of Conflict Types and Location on Trade'. The International Trade Journal 27(3), 197-224.

Marineau, J., H. Pascoe, A. Braithwaite, M. Findley, and J. Young (2018), 'The local geography of transnational terrorism'. Conflict Management and Peace Science p. 0738894218789356.

Marshall, M. G. (2016), 'Major Episodes of Political Violence (MEPV) and Conflict Regions, 1946-2015'.

Marshall, M. G., T. R. Gurr, and K. Jaggers (2016), 'Polity IV Project: Dataset UsersâĂŹ Manual'. Center for Systemic Peace.

Montgomery, J. M. and S. Olivella (2018), 'Tree-Based Models for Political Science Data'. American Journal of Political Science 62(3), 729-744.

Muchlinski, D., D. Siroky, J. He, and M. Kocher (2016), 'Comparing random forest with logistic regression for predicting class-imbalanced civil war onset data'. Political Analysis 24(1), 87-103.

Mueller, H. and C. Rauh (2018), 'Reading between the lines: Prediction of political violence using newspaper text'. American Political Science Review $\mathbf{1 1 2}(2), 358-375$.

Murdoch, J. C. and T. Sandler (2002), 'Economic Growth, Civil Wars, and Spatial Spillovers'. Journal of Conflict Resolution 46(1), 91-110.

Nardulli, P. F., S. L. Althaus, and M. Hayes (2015), 'A progressive supervisedlearning approach to generating rich civil strife data'. Sociological methodology 45(1), 148-183.

O'brien, S. P. (2010), 'Crisis early warning and decision support: Contemporary approaches and thoughts on future research'. International studies review 12(1), 87-104.

Pinto, P. M. and B. Zhu (2016), 'Fortune or evil? The effect of inward foreign direct investment on corruption'. International Studies Quarterly 60(4), 693-705.

Richani, N. (2005), 'Multinational Corporations, Rentier Capitalism, and the War System in Colombia'. Latin American Politics and Society 47(3), 113144.

Ross, M. L. (2004), 'What Do We Know about Natural Resources and Civil War?'. Journal of peace research 41(3), 337-356. 
Savun, B. and B. J. Phillips (2009), 'Democracy, Foreign Policy, and Terrorism'. Journal of Conflict Resolution 53(6), 878-904.

Schrodt, P. A. (2012), 'Conflict and Media Event Observations: Event and Actor Codebook, Version 1.1b3'.

Snyder, R. (2006), 'Does Lootable Wealth Breed Disorder? A Political Economy of Extraction Framework'. Comparative Political Studies 39(8), 943968.

Solaimani, M., R. Gopalan, L. Khan, P. T. Brandt, and B. Thuraisingham (2016), 'Spark-based political event coding'. In: 2016 IEEE Second International Conference on Big Data Computing Service and Applications (BigDataService). pp. 14-23.

START (2016), 'Global Terrorism Database [Data file].' National Consortium for the Study of Terrorism and Responses to Terrorism, Retrieved from https://www.start.umd.edu/gtd.

Ukeje, C. (2001), 'Oil Communities and Political Violence: The Case of Ethnic Ijaws in Nigeria's delta region'. Terrorism and political violence 13(4), 1536.

UNCTADSTAT (2019), 'UNCTAD Annual Report'. https://unctadstat.unctad.org/EN/.

Wade, S. J. and D. Reiter (2007), 'Does democracy matter? Regime type and suicide terrorism'. Journal of Conflict Resolution 51(2), 329-348.

Wang, W., R. Kennedy, D. Lazer, and N. Ramakrishnan (2016), 'Growing Pains for Global Monitoring of Societal Events'. Science 353(6307), 15021503.

Ward, M. D. and A. Beger (2017), 'Lessons from near real-time forecasting of irregular leadership changes'. Journal of Peace Research 54(2), 141-156.

Ward, M. D., N. W. Metternich, C. L. Dorff, M. Gallop, F. M. Hollenbach, A. Schultz, and S. Weschle (2013), 'Learning from the past and stepping into the future: Toward a new generation of conflict prediction'. International Studies Review 15(4), 473-490.

Weidmann, N. B. and M. D. Ward (2010), 'Predicting conflict in space and time'. Journal of Conflict Resolution 54(6), 883-901.

Wimmer, A., L.-E. Cederman, and B. Min (2009), 'Ethnic politics and armed conflict: A configurational analysis of a new global data set'. American Sociological Review 74(2), 316-337. 
Zhu, B. (2017), 'MNCs, rents, and corruption: Evidence from China'. American Journal of Political Science 61(1), 84-99. 